\title{
Biodata Peneliti Andi Dirpan
}

\section{Andi Dirpan}

\begin{abstract}
Abstrak
Biodata ini dibuat untuk keperluan pribadi peneliti, biodata ini berisi publikasi ilmiah selama lima tahun terakhir(Bilang, Dirpan, and Sakinah 2018; Tahir et al. 2019), Pemakalah Seminar Ilmiah (Oral Presentation) dalam 5 Tahun Terakhir. Serta Perolehan HKI dalam 10 Tahun Terakhir
\end{abstract}

Kata kunci : biodata, penelitian, seminar

A. Publikasi Artikel Ilmiah Dalam Jurnal dalam 5 Tahun Terakhir

\begin{tabular}{|c|c|c|c|c|}
\hline No & Tahun & Judul Artikel Ilmiah & Vol/No & Nama Jurnal \\
\hline 1 & 2015 & $\begin{array}{l}\text { Effect of Fruit Sizes on Resistance to } \\
\text { Gas Diffusion of Citrus }\end{array}$ & 28 & $\begin{array}{l}\text { Procedia of } \\
\text { Environmental } \\
\text { Science - Elsevier }\end{array}$ \\
\hline 2 & 2015 & $\begin{array}{l}\text { Mathematical modeling of } \\
\text { intercellular space volume of citrus } \\
\text { fruits }\end{array}$ & $41(3)$ & $\begin{array}{l}\text { Food Preservation } \\
\text { Science }\end{array}$ \\
\hline 3 & 2016 & $\begin{array}{l}\text { Improving the accuracy of } \\
\text { Intercellular Space Volume of Citrus } \\
\text { prediction by artificial neural } \\
\text { networks }\end{array}$ & 1179 & Acta horticultura \\
\hline 4 & 2016 & $\begin{array}{l}\text { Selecting Postharvest Technology } \\
\text { Method for Citrus Fruit using } \\
\text { Analytic Hierarchy Process (AHP) }\end{array}$ & $3(3)$ & KnE Life Science \\
\hline 5 & 2016 & $\begin{array}{l}\text { Intercellular Space Volume } \\
\text { Determination of Citrus Fruits Using } \\
\text { Multiple Linear Regression }\end{array}$ & $\begin{array}{l}3(2)(\text { in } \\
\text { press })\end{array}$ & $\begin{array}{l}\text { Journal of Advanced } \\
\text { Agricultural } \\
\text { Technologies }\end{array}$ \\
\hline 6 & 2016 & $\begin{array}{l}\text { Improving the measurement of } \\
\text { resistance to gas diffusion and the } \\
\text { resistance characteristics in citrus } \\
\text { iyo fruit (Citrus iyo hort. Ex Tanaka) }\end{array}$ & $42(2)$ & $\begin{array}{l}\text { Food Preservation } \\
\text { Science }\end{array}$ \\
\hline 7 & 2017 & $\begin{array}{l}\text { Evaluation of temperature and } \\
\text { relative humidity on two types of } \\
\text { zero energy cool chamber (ZECC) in }\end{array}$ & $\begin{array}{l}101(1) \\
012028\end{array}$ & $\begin{array}{l}\text { IOP Conference } \\
\text { Series: Earth and } \\
\text { Environmental }\end{array}$ \\
\hline
\end{tabular}




\begin{tabular}{|c|c|c|c|c|}
\hline & & South Sulawesi, Indonesia & & Science \\
\hline 8 & 2017 & $\begin{array}{l}\text { Physical, mechanical, and barrier } \\
\text { properties of sodium alginate/gelatin } \\
\text { emulsion based-films incorporated } \\
\text { with canola oil }\end{array}$ & $\begin{array}{l}101(1), \\
012019\end{array}$ & $\begin{array}{l}\text { IOP Conference } \\
\text { Series: Earth and } \\
\text { Environmental } \\
\text { Science }\end{array}$ \\
\hline 9 & 2017 & $\begin{array}{l}\text { The Status of Implementation of } \\
\text { Good Manufacturing Practices } \\
\text { (GMP) Shredded Fish Production in } \\
\text { UMKM Az-Zahrah, Makassar }\end{array}$ & $\begin{array}{l}101(1), \\
012040\end{array}$ & $\begin{array}{l}\text { IOP Conference } \\
\text { Series: Earth and } \\
\text { Environmental } \\
\text { Science }\end{array}$ \\
\hline 10 & 2018 & $\begin{array}{l}\text { Enzymatic production of } \\
\text { maltodextrins derived from sago } \\
\text { flour using heat-stable alpha- } \\
\text { amylase and pullulanase }\end{array}$ & $\begin{array}{l}157(1), \\
012028\end{array}$ & $\begin{array}{l}\text { IOP Conference } \\
\text { Series: Earth and } \\
\text { Environmental } \\
\text { Science }\end{array}$ \\
\hline 11 & 2018 & $\begin{array}{l}\text { The application status of Good Food } \\
\text { Production Method (GFPM) } \\
\text { production of corn crackers in SME } \\
\text { Mawar Merah Luwu Utara }\end{array}$ & $\begin{array}{l}157(1) \\
012035\end{array}$ & $\begin{array}{l}\text { IOP Conference } \\
\text { Series: Earth and } \\
\text { Environmental } \\
\text { Science }\end{array}$ \\
\hline 12 & 2018 & $\begin{array}{l}\text { The use of colour indicator as a } \\
\text { smart packaging system for } \\
\text { evaluating mangoes Arummanis } \\
\text { (Mangifera indica L. var. } \\
\text { Arummanisa) freshness }\end{array}$ & $\begin{array}{l}157(1), \\
012031\end{array}$ & $\begin{array}{l}\text { IOP Conference } \\
\text { Series: Earth and } \\
\text { Environmental } \\
\text { Science }\end{array}$ \\
\hline 13 & 2018 & $\begin{array}{l}\text { Combining an Analytic Hierarchy } \\
\text { Process and TOPSIS for Selecting } \\
\text { Postharvest Technology Method for } \\
\text { Selayar Citrus in Indonesia }\end{array}$ & $\begin{array}{l}156(1) \\
012031\end{array}$ & $\begin{array}{l}\text { IOP Conference } \\
\text { Series: Earth and } \\
\text { Environmental } \\
\text { Science }\end{array}$ \\
\hline 14 & 2018 & $\begin{array}{l}\text { Quality and Storability of Mango } \\
\text { During Zero Energy Cool Chamber } \\
\text { (ZECC) }\end{array}$ & $6 / 2$ & $\begin{array}{l}\text { International Journal } \\
\text { of Agriculture } \\
\text { System }\end{array}$ \\
\hline
\end{tabular}

B. Pemakalah Seminar Ilmiah (Oral Presentation) dalam 5 Tahun Terakhir

\begin{tabular}{|l|l|l|l|}
\hline No & $\begin{array}{l}\text { Nama Temu } \\
\text { ilmiah/Seminar }\end{array}$ & Judul Artikel Ilmiah & Waktu dan Tempat \\
\hline 1 & $\begin{array}{l}\text { The 18th World } \\
\text { Congress Of } \\
\text { CIGR, } \\
\text { Agricultural and } \\
\text { Biosystems } \\
\text { Engineering } \\
\text { Volume of Citrus by Physical } \\
\text { Measurements }\end{array}$ & $\begin{array}{l}\text { 16-19 } \\
\text { 2014. Beijing, China }\end{array}$ \\
\hline 2 & $\begin{array}{l}\text { The } \\
\text { International } \\
\text { Conference } \\
\text { on Sustainable } \\
\text { Future for } \\
\text { Human Security }\end{array}$ & $\begin{array}{l}\text { Effect of Fruit Sizes on Resistance to Gas } \\
\text { Diffusion of Citrus }\end{array}$ & $\begin{array}{l}\text { 19-21 Oktober, 2014. } \\
\text { Bali, Indonesia }\end{array}$ \\
\hline
\end{tabular}




\begin{tabular}{|c|c|c|c|}
\hline & (SUSTAIN) & & \\
\hline 3 & $\begin{array}{l}\text { 3rd Southeast } \\
\text { Asia Symposium } \\
\text { on Quality } \\
\text { Management in } \\
\text { Postharvest } \\
\text { System } \\
\text { (SEAsia2015) }\end{array}$ & $\begin{array}{l}\text { Improving the accuracy of intercellular } \\
\text { space volume of citrus prediction by } \\
\text { artificial neural networks }\end{array}$ & $\begin{array}{l}\text { 13-15 Agustus, } 2015 . \\
\text { Siem Reap, Cambodia }\end{array}$ \\
\hline 4 & $\begin{array}{l}\text { International } \\
\text { Conference on } \\
\text { Agro-industry } \\
\text { ICoA 2015 }\end{array}$ & $\begin{array}{l}\text { Selecting Postharvest Technology Method } \\
\text { for Citrus Fruit using Analytic Hierarchy } \\
\text { Process (AHP) }\end{array}$ & $\begin{array}{l}\text { 7-9 November, } 2015 . \\
\text { Matsuyama, Japan }\end{array}$ \\
\hline 5 & $\begin{array}{l}\text { International } \\
\text { Sago } \\
\text { Symposium } \\
2016\end{array}$ & $\begin{array}{l}\text { An AHP approach to prioritize traditional } \\
\text { sago processed foods in South Sulawesi, } \\
\text { Indonesia }\end{array}$ & 23 juli 2016 \\
\hline 6 & $\begin{array}{l}\text { Academic } \\
\text { Conference on } \\
\text { Mechanical and } \\
\text { Control } \\
\text { Engineering } \\
2016 \\
\end{array}$ & $\begin{array}{l}\text { Aplikasi Analytical Hierarchy Process } \\
\text { (AHP) dalam Menyeleksi Teknologi Pasca } \\
\text { Panen Terbaik untuk Buah Jeruk Selayar }\end{array}$ & $\begin{array}{l}7 \text { November, } 2016 . \\
\text { Makassar, Indonesia }\end{array}$ \\
\hline 7 & $\begin{array}{l}\text { The International } \\
\text { Conference on } \\
\text { Natural Products } \\
\text { and Bioresource } \\
\text { Sciences } 2017 \\
\text { (ICONPROBIOS } \\
\text { 2017) }\end{array}$ & $\begin{array}{l}\text { Evaluation of temperature and relative } \\
\text { humidity on two types of zero energy cool } \\
\text { chamber (ZECC) in South Sulawesi, } \\
\text { Indonesia }\end{array}$ & $\begin{array}{l}\text { October 23-24, } 2017 \text { at } \\
\text { Balai Kartini } \\
\text { (Convention Center), } \\
\text { Jakarta, Indonesia }\end{array}$ \\
\hline 8 & $\begin{array}{l}\text { The First } \\
\text { International } \\
\text { Conference On } \\
\text { Food Security } \\
\text { And Sustainable } \\
\text { Agriculture In } \\
\text { The Tropics } \\
2017\end{array}$ & $\begin{array}{l}\text { Use of Color Indicator as Smart Packaging } \\
\text { System for Evaluating Mangoes } \\
\text { Arummanis (Mangifera indica L. Var } \\
\text { Arummanisa) Freshness }\end{array}$ & $\begin{array}{l}\text { October 24-25, } 2017 \text { at } \\
\text { Balai Kartini Swiss- } \\
\text { belhotel. Makassar, } \\
\text { Indonesia }\end{array}$ \\
\hline 9 & $\begin{array}{l}\text { Academic } \\
\text { Conference on } \\
\text { Mechanical, } \\
\text { Agrotechnology, } \\
\text { and Control } \\
\text { (AC-MAC) } 2017\end{array}$ & $\begin{array}{l}\text { Perbandingan kinerja dua tipe "zero } \\
\text { energy cool chamber" (ZECC) dalam } \\
\text { memperpanjang masa simpan produk hasil } \\
\text { pertanian }\end{array}$ & $\begin{array}{l}\text { Senin, } 27 \text { November } \\
\text { 2017. Aula Politeknik } \\
\text { ATI Makassar }\end{array}$ \\
\hline 10 & $\begin{array}{l}\text { ICREST } \\
\text { "International } \\
\text { Conference of }\end{array}$ & $\begin{array}{l}\text { Determining the Best Treatment of Juice } \\
\text { Java Plum as Functional Drink Using } \\
\text { Analytic Hierarcy Process (AHP) }\end{array}$ & $\begin{array}{l}\text { Universitas } \\
\text { Muhammadiyah } \\
\text { Parepare, Sulawesi }\end{array}$ \\
\hline
\end{tabular}




\begin{tabular}{|c|c|c|c|}
\hline & $\begin{array}{l}\text { Research on } \\
\text { Education Social } \\
\text { Science and } \\
\text { Technology" } \\
2018\end{array}$ & & $\begin{array}{l}\text { Selatan, pada tanggal } \\
28-29 \text { April } 2018\end{array}$ \\
\hline 11 & $\begin{array}{l}\text { The 1st } \\
\text { International } \\
\text { Conference on } \\
\text { Global Issue for } \\
\text { infrastructure, } \\
\text { environment \& } \\
\text { socio-economic } \\
\text { development }\end{array}$ & $\begin{array}{l}\text { Community service in Kecamatan } \\
\text { Patampanua: Improving community's } \\
\text { economy and prosperity through the } \\
\text { establishment of pisang sale's UMKM }\end{array}$ & $\begin{array}{l}\text { Universitas } \\
\text { Hasanuddin, Makassar, } \\
30 \text { Agustus }-1 \\
\text { September } 2018\end{array}$ \\
\hline 12 & $\begin{array}{l}\text { 6th International } \\
\text { Conference on } \\
\text { Sustainable } \\
\text { Agriculture, } \\
\text { Food and Energy }\end{array}$ & $\begin{array}{l}\text { Quality And Storability Of Tomato During } \\
\text { Zero Energy Cool Chamber (ZECC) } \\
\text { Storage }\end{array}$ & $\begin{array}{l}\text { October } 18-21,2018 \text { in } \\
\text { Manila, The } \\
\text { Philippines }\end{array}$ \\
\hline 13 & & & \\
\hline
\end{tabular}

C. Karya Buku dalam 5 Tahun Terakhir

\begin{tabular}{|c|c|c|c|c|}
\hline No & Judul Buku & Tahun & Jumlah halaman & Penerbit \\
\hline 1 & Ensiklopedia & 2017 & 611 & PATPI bekerja sama \\
& Produk Pangan & & & dengan PT. Penerbit \\
& Indonesia & & & IPB press \\
& (ISBN : 978- & & & \\
& $602-440-183-2$ & & & \\
\hline
\end{tabular}

D. Perolehan HKI dalam 10 Tahun Terakhir

\begin{tabular}{|c|c|c|c|c|}
\hline No & Judul/Tema HKI & Tahun & Jenis & Nomor P/ID \\
\hline 1 & $\begin{array}{c}\text { Formula dan proses } \\
\text { pembuatan indikator } \\
\text { kesegaran buah mangga } \\
\text { arumanis (Mangifera } \\
\text { indica L. Var } \\
\text { Arumanis) sebagai } \\
\text { elemen kemasan cerdas }\end{array}$ & 2018 & Paten & P15201802794 \\
\hline 2 & Golsin (Gula Aren) & 2018 & & \\
\hline
\end{tabular}




\section{References}

Bilang, Mariyati, Andi Dirpan, and Nur Sakinah. 2018. "Pengaruh Pemanasan Berulang (Tyndalisasi) Saus Spaghetti Ikan Tuna Terhadap Daya Terima Dan Pendugaan Umur Simpan Dengan Metode Akselerasi Model Persamaan Arrhenius." Canrea Journal 1(2):98-106.

Tahir, Mulyati M., Jumriah Langkong, Abu Bakar Tawali, and Nurlaila Abdullah. 2019. “KAJIAN PENGARUH JENIS PENGERING DAN KONSENTRASI MALTODEKSTRIN TERHADAP PRODUK MINUMAN TEH - SECANG EFFERVESCENT ( Study Effect Dryer and Concentration of Maltodextrin to Drink Tea Products - Sappan Wood Effervescent ) E-ISSN : 2621-9468 Memerlukan Penamba." Canrea Journal 2(1). 